\title{
Synthesis of Nanoparticles - Why only white and not yellow?
}

\author{
Vinita Ernest ${ }^{1}$, Joyce Nirmala $\mathbf{M}^{2 *}$ and R Nagarajan ${ }^{2 *}$ \\ ${ }^{1}$ Department of Biotechnology, DKM College for Women (Autonomous), Sainathapuram, Vellore-1, India \\ ${ }^{2}$ Department of Chemical Engineering, Indian Institute of Technology Madras, Chennai, India
}

\begin{abstract}
Received: June 08, 2017; Accepted: June 12, 2017; Published: June 14, 2017
*Corresponding author: Nirmala MJ, Department of Chemical Engineering, Indian Institute of Technology Madras, Chennai, India. E-mail: joycegitz@ gmail.com,
\end{abstract}

Nagarajan R, Department of Chemical Engineering, Indian Institute of Technology Madras, Chennai, India. E-mail: nag@iitm.ac.in

Eco-friendly, bio-mimetic and bio-synthetic approaches have succeeded to its peak in the bottom-up synthesis of nanoparticles. Various metallic, organic and inorganic nanoparticles which are of immense interest to researchers in the field of drug delivery, drug targeting, sensing, personal care are being synthesized with various plant extracts, biomolecules such as glucose, starch, amino-acids, leaves, roots, barks and other chemical free ingredients [1]. The microbial enzymes or the plant phyto-chemicals with anti-oxidant or reducing properties are found responsible for reduction of metal salts into their corresponding metal nanoparticles. The bio-reduction of metal ions by combinations found in the extracts of certain organisms such as enzymes, proteins, amino acids, polysaccharides and vitamins is environmentally benign, yet chemically complex. The use of peptides and proteins are at present in high demand for the fabrication of nano-sized materials due to their large structural and functional diversity, availability and utilization in the manipulation of material properties [2,3]. Moreover, biotemplatedirected synthesis of inorganic nanoparticles using starch offered a "greener" approach than the conventional methods available as the conditions of reaction and production were generally mild.

The application oriented usage of thus synthesized nanoparticles is that they possess reduced toxic levels, economical and low-cost production of nanoparticles in bulk quantities with controlled size and shape, and the possible functionalization of the biomolecules over the surface of the synthesized nanoparticles [4]. They possess a wide range of applications from sensing to delivery.

Though egg-white (albumin) is used for the synthesis of nanoparticles, the egg- yolk stands as a greater potential source for synthesis which is yet to be explored [5,6]. Egg yolk is a rich source of cholesterol and other important proteins, amino acids, minerals, vitamins, biotin, vital nutrients such as lecithin, phosvitin, carotenoids and other bio-active components which aids in treatment and inhibition of chronic and other infectious diseases [7]. There are only two reports as of 2017 for the usage of quail egg yolk for the synthesis of platinum and gold nanoparticles [8]. The above said method had yielded well dispersed nanoparticles of size between 7 and $50 \mathrm{~nm}$ without any chemical reducing agent. Furthermore, the usage of egg yolk should be explored at different levels in order to discover the potential of the surface functionalization (protein-corona nanoparticle) which paves way for a plethora of applications in the field of electrochemistry, catalysis, pharmaceutics, biosensing and drug delivery.

\section{Acknowledgement}

The authors thank DST-SERB, Government of India for all sources of support.

\section{References}

1. Mohanpuria P, K Nisha R, Yadav SK. Biosynthesis of nanoparticles: technological concepts and future applications. Journal of Nanoparticle Research. 2008;10(3):507-517. doi: 10.1007/s11051-007-9275-x

2. Aubin-Tam M-E, Hamad-Schifferli K. Structure and function of nanoparticle-protein conjugates. Biomed Mater. 2008;3(3):034001. doi: 10.1088/1748-6041/3/3/034001

3. Ernest V, Mukherjee A, Chandrasekaran N. Interaction of Colloidal Ag Nanoparticles with Bovine Serum Albumin. In Encyclopedia of Metalloproteins. Edited by Uversky VN, Kretsinger RH, Permyakov. EA. Springer. 2013.

4. Vimalanathan AB, Ernest V, Arumugasamy K, Tyagi MG. Biosynthesis of silver nano-particles by the bacterium Micrococcus luteus. International Journal of Applied Biology and Pharmaceutical Technology. 2013;4(1):77-83.

5. Bagheri S, Shameli K, Abd Hamid SB. Synthesis and characterization of anatase titanium dioxide nanoparticles using egg white solution via Sol-Gel method. Journal of Chemistry. 2013.

6. Lu R, Yang D, Cui D, Wang Z, Guo L. Egg white-mediated green synthesis of silver nanoparticles with excellent biocompatibility and enhanced radiation effects on cancer cells. Int J Nanomedicine. 2012;7:21012107. doi: $10.2147 /$ IJN.S29762

7. Miranda J, Anton X, Redondo-Valbuena C, Roca-Saavedra P, Rodriguez J, Lamas A, etc. Egg and Egg-Derived Foods: Effects on Human Health and Use as Functional Foods. Nutrients. 2015;7(1):706-729. doi: 10.3390/nu7010706

8. Nadaroglu H, Gungor AA, Ince S, Babagil A. Green synthesis and characterisation of platinum nanoparticles using quail egg yolk. Spectrochim Acta A Mol Biomol Spectrosc. 2017;172:43-47. doi: 10.1016/j.saa.2016.05.023 